\title{
Drug-resistant tuberculosis: emerging treatment options
}

This article was published in the following Dove Press journal:

Clinical Pharmacology:Advances and Applications

12 December 201 I

Number of times this article has been viewed

\section{Meghna Adhvaryu' \\ Bhasker Vakharia ${ }^{2}$}

'Department of Biotechnology, SRK Institute of Computer Education and Applied Sciences, ${ }^{2}$ R\&D,

Bhuma Research in Ayurvedic and Herbal Medicine, Surat, Gujarat, India
Correspondence: Meghna Adhvaryu Department of Biotechnology, SRK Institute of Computer Education and Applied Sciences, MTB College Campus, Athwalines, Surat 39500I, India

$\mathrm{Tel}+9 \mid 26$ I224 0172

$\mathrm{Fax}+9|26| 2240170$

Email meghna.adhvaryu@gmail.com
Abstract: Multidrug-resistant tuberculosis has emerged worldwide, with an increasing incidence due to failure of implementation of apparently effective first-line antituberculous therapy as well as primary infection with drug-resistant strains. Failure of current therapy is attributed to a long duration of treatment leading to nonadherence and irregular therapy, lack of patient education about the disease, poverty, irregular supply by care providers, drug-drug interactions in patients coinfected with human immunodeficiency virus (HIV), inadequate regulations causing market overlap and irresponsible drug usage in the private sector, and lack of research, with no addition of new drugs in the last four decades. Present standards of care for the treatment of drugsusceptible tuberculosis, multidrug-resistant tuberculosis, tuberculosis-HIV coinfection, and latent tuberculosis infection are all unsatisfactory. Since 2000, the World Health Organization (WHO) has focused on drug development for tuberculosis, as well as research in all relevant aspects to discover new regimens by 2015 and to eliminate tuberculosis as a public health concern by 2050 . As a result, some 20 promising compounds from 14 groups of drugs have been discovered. Twelve candidates from eight classes are currently being evaluated in clinical trials. Ongoing research should prioritize identification of novel targets and newer application of existing drugs, discovery of multitargeted drugs from natural compounds, strengthening host factors by immunopotentiation with herbal immunomodulators, as well as protective vaccines before and after exposure, consideration of surgical measures when indicated, development of tools for rapid diagnosis, early identification of resistant strains, and markers for adequacy of treatment and an integrative approach to fulfill WHO goals. However, regulatory control over the drug market, as well as public-private partnership to use health program facilities to track patients and ensure completion of adequate therapy will be necessary to exploit fully the potential of the newer regimens to eliminate tuberculosis.

Keywords: tuberculosis, vaccine, biomarkers, drug resistance, human immunodeficiency virus

\section{Introduction}

Drug-resistant tuberculosis is widespread and found in all countries surveyed. It emerges as a result of treatment mismanagement, and is passed from person to person in the same way as drug-sensitive tuberculosis. Multidrug-resistant tuberculosis is caused by bacteria that are resistant to the most effective antituberculous drugs, ie, isoniazid and rifampicin. There were an estimated 44,0000 new multidrugresistant tuberculosis cases in 2008, and 150,000 deaths from the disease. It was estimated that $3.3 \%$ of all new tuberculosis cases in 2009 were multidrug-resistant. In 2010, the largest World Health Organization (WHO) multidrug-resistant tuberculosis survey reported the highest rates ever of multidrug-resistant tuberculosis, 
with peaks of up to $28 \%$ of new cases in some settings of the former Soviet Union. Many countries have developed plans to address multidrug-resistant tuberculosis, but the response globally is still inadequate. Highest absolute numbers of multidrug-resistant tuberculosis cases are in China and India, accounting for nearly $50 \%$ of the worldwide burden.

Extensively drug-resistant tuberculosis is caused by bacteria that are resistant to isoniazid and rifampicin (ie, multidrug-resistant) as well as all fluoroquinolones and any of the second-line antituberculous injectable drugs (amikacin, kanamycin, capreomycin). These forms of tuberculosis do not respond to standard treatment comprising 6 months of first-line antituberculous drugs, and can take at least two years to treat with drugs that are less potent, more toxic, and much more expensive. On average, $5.4 \%$ of multidrug-resistant tuberculosis cases have been found to be extensively drug-resistant, as confirmed by surveillance in 58 countries, and this would account for around 25,000 cases of extensively drug-resistant tuberculosis emerging every year. ${ }^{1,2}$
Rifampicin is a member of the last novel class of antibiotics introduced in 1963 for first-line treatment of tuberculosis. Drugs in this class are part of a 6-month regimen that is ineffective against multidrug-resistant and extensively drugresistant tuberculosis, and have unfavorable drug interactions with many antiretroviral drugs. Except for the addition of the fluoroquinolones as second-line therapy, nothing was added until 2000 (Figure 1). Since then, over 12 compounds have progressed to the clinical development pipeline for treatment of tuberculosis (Table 1). These compounds, if properly developed, have the potential to become part of a future regimen that could greatly improve the global effort to control tuberculosis. ${ }^{3}$ The potential benefits of new drugs in development have been investigated by a modeling study, which suggests that the combination of a 2-month treatment regimen that cures $95 \%$ of multidrug-resistant tuberculosis, a generalized nucleic acid amplification test for diagnosis, and a joint preexposure as well as post-exposure vaccine could potentially reduce the incidence of the disease by $71 \%$ in 2050 . Addition of preventive treatment for latent tuberculosis infection to this regimen might reduce the incidence by $94 \%{ }^{4}$

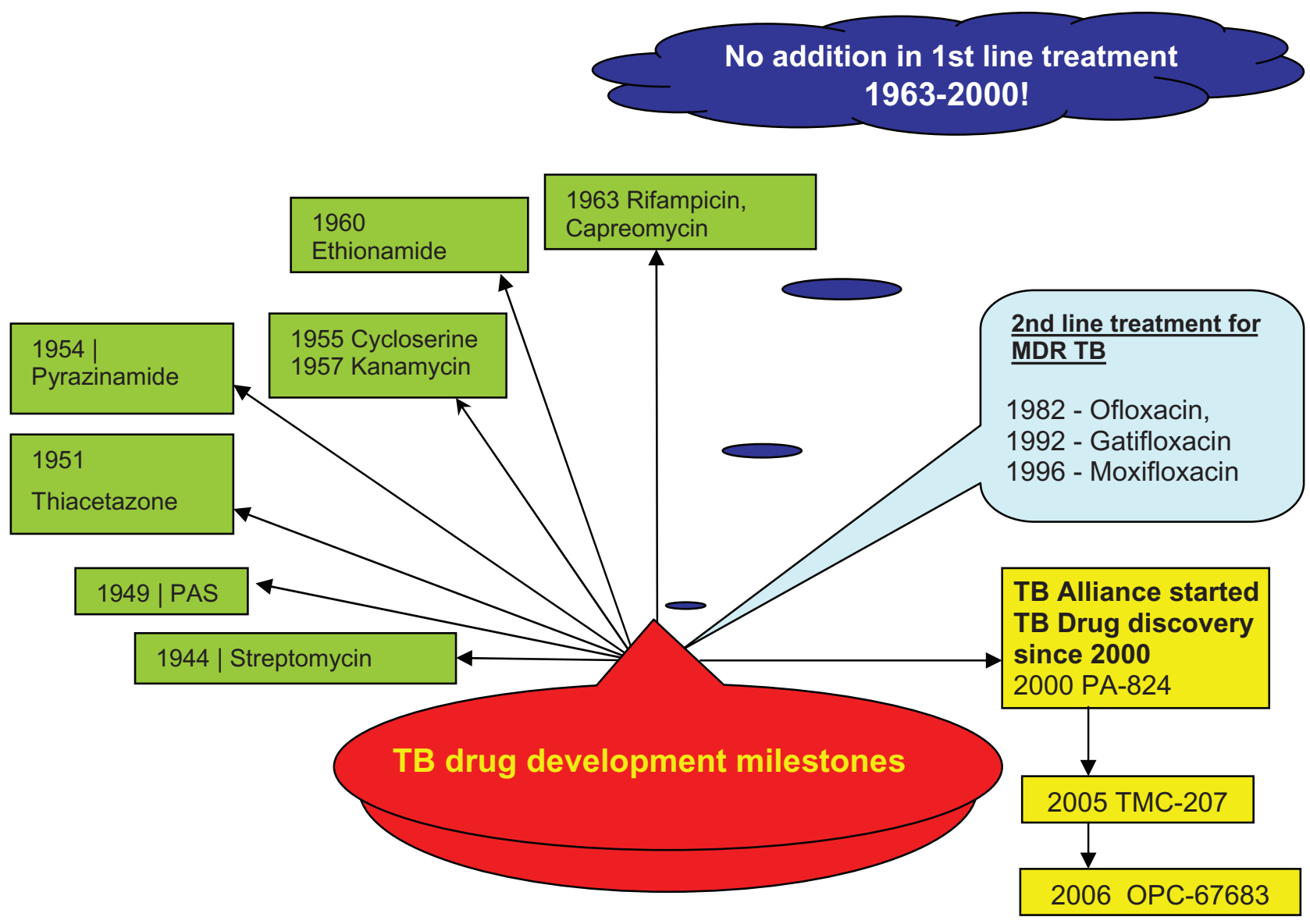

Figure I TB drug development time-line.

Abbreviations: TB, tuberculosis; MDR, multidrug-resistant. 
Table I Tuberculosis clinical development programs

\begin{tabular}{|c|c|c|c|}
\hline Groups & Compound & Development stage & Sponsor/coordinator \\
\hline Rifamycins & Rifapentine & Phase II/III & CDC TBTC, sanofi-aventis \\
\hline \multirow[t]{4}{*}{ Fluoroquinolone } & Gatifloxacin & Phase III & European Commission; IRD; WHO/TDR; Lupin \\
\hline & Moxifloxacin & Phase II/III & $\begin{array}{l}\text { Bayer; TB Alliance; CDC; University College London; } \\
\text { Johns Hopkins University }\end{array}$ \\
\hline & DC-159a & Preclinical & Japan Anti-Tuberculosis Association, \\
\hline & & & JATA Daiichi-Sankyo Pharmaceutical Co \\
\hline \multirow[t]{3}{*}{ Oxazolidinone } & Linezolid (low dose) & Phase II & CDC TBTC, Pfizer, various universities \\
\hline & PNU- 100480 & Phase I & Pfizer \\
\hline & AZD5847 & Phase I & AstraZeneca \\
\hline Diarylquinoline & TMC207 & Phase II & Johnson \& Johnson (Tibotec) \\
\hline \multirow[t]{2}{*}{ Nitroimidazole } & OPC67683 & Phase II & Otsuka Pharmaceutical \\
\hline & PA824 & Phase II & TB Alliance \\
\hline Pyrrole & LL3858 & Phase I & Lupin \\
\hline Diamine & SQI09 & Phase II & Sequella \\
\hline Dipiperidines & SQ609 & EBA & Sequella \\
\hline Capuramycins & SQ64I & EBA & Sequella \\
\hline Isothiazoloquinolone & $\mathrm{ACH}-702$ & Preclinical & Achillion Pharmaceuticals \\
\hline \multirow[t]{3}{*}{ Caprazene nucleoside } & Caprazamycin & Preclinical & MCRF, Tokyo, Japan \\
\hline & & & Lilly TB Drug Discovery Initiative \\
\hline & & & NIAID, IDRI, Lilly, YourEncore \\
\hline Benzothiozinones & BZT043 & EBA & EPFL School of Life Sciences \\
\hline Imidazopyridine & Q20I & EBA & Quro Science, Inc \\
\hline \multirow[t]{3}{*}{ Riminophenazines } & Phenoxazine and & EBA and Phase I & Institute of Materia Medica, China and Beijing \\
\hline & asymmetrical & & Tuberculosis and Thoracic Tumor \\
\hline & riminophenazine series & & Research Institute \\
\hline
\end{tabular}

Abbreviations: CDC, Centers for Disease Control and Prevention; TBTC, Tuberculosis Trials Consortium; TDR, Special Programme for Research and Training in Tropical Diseases; EBA, early bactericidal activity; MCRF, Microbial Chemistry Research Foundation; NIAID, National Institute of Allergy and Infectious Diseases; EPFL, École Polytechnique Fédérale de Lausanne; GSK, GlaxoSmithKline; IDRI, Infectious diseases research institute; WHO, World Health Organization; TB, tuberculosis.

\section{Current treatment for multidrug-resistant tuberculosis}

Multidrug-resistant tuberculosis has become increasingly prevalent, and an extensively drug-resistant form is emerging. ${ }^{5}$ Combinations of first-line and second-line drugs are useful for the treatment of multidrug-resistant and extensively drug-resistant tuberculosis according to results of drug susceptibility testing. Second-line drugs include aminoglycosides (kanamycin and amikacin), cycloserine, terizidone, ethionamide, prothionamide, capreomycin, aminosalicylic acid, and fluoroquinolones (including ofloxacin, levofloxacin, gatifloxacin, and moxifloxacin). The percentage of patients with multidrug-resistant tuberculosis who are cured is estimated to be no more than $69 \%$, even when treated for more than 18 months with directly observed treatment. ${ }^{6}$ In 2008 , only about $1 \%$ of cases of multidrugresistant tuberculosis were estimated to have received proper treatment according to the standards recommended by the WHO. ${ }^{7}$ Containment of the spread of multidrug-resistant and extensively drug-resistant tuberculosis will be extremely difficult without treatment regimens that are shorter, safer, more effective, and less expensive than those presently available. New drugs with novel mechanisms of action are needed for effective management of multidrug-resistant and extensively drug-resistant tuberculosis. ${ }^{4}$ One study documented the emergence of new forms of totally drugresistant bacilli among patients with multidrug-resistant disease. The isolation of totally drug-resistant strains from multidrug-resistant tuberculosis patients from different regions is alarming, and indicates possible dissemination of such strains in Asian countries. ${ }^{8}$

\section{Ideal profile of new drug/regimen}

Duration of the curative regimen must be shortened to less than 2 months or, ideally, to days (Figure 2). It should be

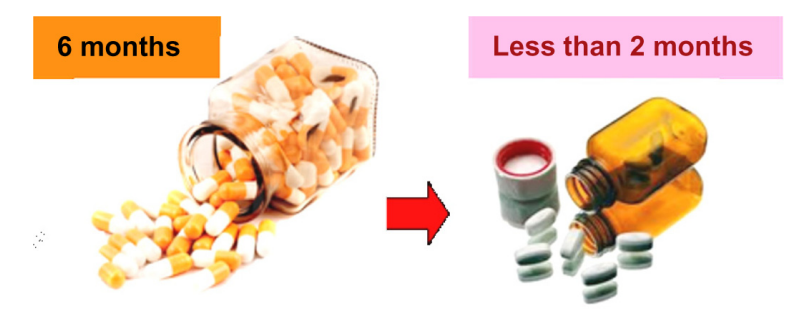

Figure 2 TB drug regimen goal. Abbreviation: TB, tuberculosis. 
effective against multidrug-resistant and extensively drugresistant tuberculosis due to a novel mechanism of action and should not have cross-resistance with the classical regimen. It should be devoid of toxicity and have no drugdrug interactions with antiretroviral therapies. It should be possible to administer once a day or intermittently by the oral route and must be affordable in resource-scarce regions with a high incidence of multidrug-resistant and extensively drug-resistant tuberculosis. ${ }^{9}$

Present clinical trials are testing new combinations of drugs for their safety and efficacy in treatment durations of 6 months for drug-susceptible tuberculosis, as well as new drugs in optimized regimens for multidrug-resistant tuberculosis. ${ }^{10}$ A growing pipeline of single compounds underscores the needs for devising and testing optimal drug combinations that would be suitable for treatment of tuberculosis in all its forms, and the necessary collaboration of pharmaceutical companies, academia, research institutions, donors, and regulatory authorities. ${ }^{10}$

\section{New antituberculous medicines in the pipeline Fluoroquinolones}

Fluoroquinolones are broad-spectrum antimicrobial drugs that target DNA gyrase. Several members of this class have been used as second-line drugs for the treatment of multidrug-resistant tuberculosis. Gatifloxacin and moxifloxacin have shown better in vitro activity than ofloxacin and ciprofloxacin against Mycobacterium tuberculosis. ${ }^{1-13}$ They have little interaction with cytochrome P450 (CYP), so could be coadministered with antiretroviral drugs without fear of drug-drug interactions. Also, they have the potential to shorten the duration of the regime by improved sterilization activity. ${ }^{14}$ The fluoroquinolones have been safe and well tolerated in most of the studies involving drug combination trials for earlier sputum culture conversion, ${ }^{15}$ although gatifloxacin has been shown to increase the risk of hospitalization for dysglycemia in patients with and without diabetes. ${ }^{16}$ Use of fluoroquinolones should be avoided in patients with risk factors for prolongation of the QTc interval or tendinopathy. All fluoroquinolones should be used with caution in patients with a history of seizure disorders, and may cause phototoxicity and Clostridium difficile-associated diarrhea. ${ }^{16}$

\section{Gatifloxacin}

A trial was conducted by the South African Medical Research Council in Durban, South Africa, in patients with newly diagnosed pulmonary tuberculosis with and without HIV coinfection to measure the antituberculous activity of gatifloxacin in the first 2 months of therapy when compared with the standard treatment recommended by the WHO, and two other similar regimens containing either ofloxacin or moxifloxacin. Treatment with either the gatifloxacin-containing or moxifloxacin-containing regimen was shown to be significantly more active than either the standard regimen or the ofloxacin-containing regimen after 2 months of therapy. ${ }^{13}$ Phase III trials are in progress investigating if treatment of drug-susceptible tuberculosis can be shortened to 4 months by substitution of gatifloxacin for ethambutol. ${ }^{4}$

\section{Moxifloxacin}

Moxifloxacin improves culture conversion in the initial phase of tuberculosis treatment when substituted for ethambutol. ${ }^{17,18}$ Substitution of moxifloxacin for isoniazid resulted in a small but statistically nonsignificant increase in culture negativity at week $8 .{ }^{19}$

\section{Oxazolidinones}

Oxazolidinones exert their antimicrobial activity via inhibition of protein synthesis by binding to the 70 S ribosomal initiation complex. ${ }^{20}$ These compounds have a broad spectrum of activity against anaerobic and Gram-positive aerobic bacteria, as well as mycobacteria. ${ }^{21}$

\section{Linezolid}

Linezolid is the first approved oral antibiotic of the oxazolidinone class, and has demonstrated in vitro activity against both drug-susceptible and drug-resistant isolates of M. tuberculosis without showing cross-resistance with the standard antituberculous agents. ${ }^{22}$ Linezolid has been used off-label in combination regimens to treat multidrugresistant tuberculosis, but its precise contribution to the efficacy of such combinations is unclear. However, one case series has reported a successful outcome in extensively drug-resistant tuberculosis, with manageable side effects. ${ }^{23,24}$ In a retrospective study, the majority of patients with multidrug-resistant tuberculosis on linezolid had favorable treatment outcomes, although treatment was complicated by adverse events that required extensive clinical management. ${ }^{25}$ Long-term use of linezolid has been associated with cumulative toxicity, including peripheral and optic neuropathy. ${ }^{26}$ A low-dose trial with linezolid $300 \mathrm{mg}$ /day proved useful for increasing the chances of culture conversion in the treatment of patients with intractable multidrug-resistant 
or extensively drug-resistant tuberculosis, and had a lower incidence of neurotoxicity compared with a $600 \mathrm{mg} /$ day dose of linezolid. ${ }^{27}$ Further research is underway using a $300 \mathrm{mg}$ dose of linezolid for multidrug-resistant and extensively drug-resistant tuberculosis.

\section{PNU 100480}

PNU 100480 is an analog of linezolid that is being developed for tuberculosis, and a Phase I trial is in progress. ${ }^{28}$ It has shown slightly better activity than linezolid against M. tuberculosis in vitro, but substantially improved activity in mouse models of tuberculosis. ${ }^{29}$ The combination of PNU100480, moxifloxacin, and pyrazinamide, which does not contain either rifampin or isoniazid, was also more active than rifampin, isoniazid, and pyrazinamide. These results suggest that PNU100480 may have the potential to shorten the duration of therapy significantly for drug-susceptible and multidrug-resistant tuberculosis. ${ }^{30,31}$

\section{AZD 5847}

AZD 5847 is anoxazolidinone, the chemical structure and preclinical study results for which have not been made available to the public. However, a Phase I trial is going on, with an ascending dose study of the pharmacokinetics, safety, and tolerability of the compound.

\section{Rifamycins}

Recent renewed interest in high-dose rifamycins, including daily rifapentine therapy, is a result of the integration of pharmacokinetic and pharmacodynamic principles into the development of antituberculous drugs. Since the introduction of rifampicin four decades ago, the rifamycins have been cornerstone agents in the modern shortcourse regimen due to their relatively strong sterilizing activity. ${ }^{32,33}$

Rifapentine is a congener with more potent in vitro activity than rifampicin (minimum inhibitory concentration $0.06 \mathrm{mg} / \mathrm{mL}$ versus $0.25 \mathrm{mg} / \mathrm{mL}$ ) ${ }^{34}$ and a longer serum half-life (11-18 hours versus 2-4 hours). ${ }^{35,36}$ Its development as an antituberculous drug was solely to provide an option for once-weekly supervised therapy during the continuation phase. Use of rifapentine at 7.5 or $10 \mathrm{mg} / \mathrm{kg}$ (corresponding to typical human doses of 450 or $600 \mathrm{mg}$ ) in daily regimens or $15 \mathrm{mg} / \mathrm{kg}$ (corresponding to typical human doses of $900 \mathrm{mg}$ ) in a three-times weekly regimen in combination with isoniazid and pyrazinamide shortened the treatment duration needed to prevent relapse by $50 \%{ }^{37}$ Higher rifapentine doses were even more effective. ${ }^{37,38}$
The lone Phase III trial involving rifapentine includes two experimental arms in which initial-phase treatment is with rifampicin $10 \mathrm{mg} / \mathrm{kg}$, moxifloxacin $400 \mathrm{mg}$, pyrazinamide, and ethambutol, while continuation-phase treatment is either twice-weekly rifapentine $15 \mathrm{mg} / \mathrm{kg}$ and moxifloxacin for 2 months or once-weekly rifapentine $20 \mathrm{mg} / \mathrm{kg}$ and moxifloxacin for 4 months. Three Phase II trials will evaluate daily rifapentine-based regimens. A randomized, double-blind trial conducted by the US Centers for Disease Control and Prevention will evaluate the safety, tolerability, and efficacy of replacing rifampicin $10 \mathrm{mg} / \mathrm{kg}$ with rifapentine $10 \mathrm{mg} / \mathrm{kg}$ administered 5 days per week during the first 8 weeks of daily treatment. In a second trial conducted in South Africa, investigators from Johns Hopkins University and Cape Town University will evaluate the dose-response of two daily rifapentine doses $(7.5$ and $10 \mathrm{mg} / \mathrm{kg}$ ) administered 7 days per week in place of rifampicin during the first 8 weeks of treatment. In a third trial, investigators from Johns Hopkins University and the Federal University of Rio de Janeiro will evaluate the efficacy of a daily regimen of rifapentine $7.5 \mathrm{mg} / \mathrm{kg}$ combined with moxifloxacin, pyrazinamide, and ethambutol administered 7 days per week for the first 8 weeks in a trial conducted in Brazil. Rifapentine, in combination with isoniazid and pyrazinamide, shortened the treatment duration in a mouse model. ${ }^{39}$ In clinical trials of rifapentine used at approved doses, relapse rates are higher than with rifampin-containing regimens. ${ }^{40}$

\section{Diarylquinoline}

Diarylquinoline (TMC-207) is an ATP synthase inhibitor discovered by high-throughput screening against Mycobacterium smegmatis. ${ }^{4}$ It is highly potent against drug-susceptible and drug-resistant strains of M. tuberculosis. In June 2009, Tibotec (a subsidiary of Johnson \& Johnson) published preliminary stage 1 data from a double-blind, placebo-controlled, randomized Phase II trial showing a reduced time to culture conversion and a higher number of culture conversions after 8 weeks of a standard background regimen plus TMC207 in patients with multidrug-resistant tuberculosis. The compound was safe and well tolerated over the 8-week treatment period, and only nausea occurred significantly more frequently among patients in the TMC207 group than among those in the placebo group. ${ }^{41}$ In the second open-label Phase II trial, patients with newly diagnosed sputum smear-positive, multidrug-resistant pulmonary tuberculosis have been enrolled. Enrollment has now concluded, with 234 patients enrolled, and primary data are expected to be available in 2011. The trial is expected to conclude in January 2013. There is some 
evidence to suggest that TMC207 may affect antiretroviral drug levels, so Tibotec has carried out a Phase I, open-label, single-sequence, drug-drug interaction trial to investigate the pharmacokinetic interaction between steady-state nevirapine and single-dose TMC207 in HIV-infected subjects. The trial was completed in June 2010, but no results have been posted or published as yet. A similar but randomized crossover study of the interaction with lopinavir/ritonavir in healthy subjects has been completed by Tibotec. The National Institute of Allergy and Infectious Diseases has also completed a Phase I safety, tolerability, and pharmacokinetic interaction study of single-dose TMC207 and efavirenz in healthy volunteers, but no results are as yet available to the public. Tibotec is the only drug developer that has got approval from the European Medicines Agency for a pediatric development plan for future clinical studies of TMC207 in children to establish safe and effective dosing based on age and development. ${ }^{42}$

\section{Nitroimidazole}

This class of compounds can trace its history back to the 1970s, when Ciba-Geigy in India investigated a series of nitroimidazoles for their potential role as radiosensitizing agents. ${ }^{43}$ It was later discovered that many of these compounds possessed antimicrobial activity, including activity against $M$. tuberculosis. However, when the lead compound (CGI-17341) was found to be mutagenic in the Ames assay, further development was halted. ${ }^{44}$ Two members of this class (OPC-67683, PA-824) are currently in Phase II clinical trials for a tuberculosis indication and seem devoid of the mutagenicity that plagued many compounds in this class. ${ }^{45,46}$

\section{PA-824}

PA-824 was selected from a library of 700 newly synthesized nitroimidazo-oxazines (also described as nitroimidazopyrans) as the compound having the most potent activity in a murine model. Its minimum inhibitory concentration ranges from $\leq 0.015$ to $0.25 \mathrm{mg} / \mathrm{mL}$ against susceptible strains, as well as strains resistant to the commonly used first-line and second-line drugs. ${ }^{45}$ PA- 824 is a prodrug that is activated by a bacterial deazaflavin (F420)-dependent nitroreductase known as Ddn (Rv3547). ${ }^{47,48}$ The reactive intermediate(s) of PA-824 exert antituberculous activity via at least one novel mechanism, including inhibition of ketomycolic acid synthesis in the cell wall, inhibition of protein synthesis, and generation of intracellular nitric oxide. ${ }^{46,47}$ Like TMC207, PA-824 is active against nonreplicating persisters in the in vitro Wayne model ${ }^{46,49}$ and those selected by treatment of 100-day-old cultures with or without high concentrations of rifampicin, indicating its significant sterilizing activity. ${ }^{50}$ PA-824 demonstrates dose-dependent bactericidal and sterilizing activity in a murine model of tuberculosis. ${ }^{49,51}$

Combination of PA-824 with rifampicin and pyrazinamide results in more rapid lung culture conversion than the standard first-line regimen of isoniazid, rifampicin, and pyrazinamide..$^{52,53}$ The combination of PA- 824 with moxifloxacin and pyrazinamide cures mice more rapidly than the first-line regimen, suggesting that PA-824 may be capable of shortening the duration of treatment of drug-susceptible as well as multidrug-resistant or extensively drug-resistant tuberculosis. ${ }^{54}$ Phase I studies demonstrated less than doseproportional increases in drug levels, reaching a plateau at $600 \mathrm{mg}$ in a multidose study. The maximal serum concentration was $3.8 \mathrm{mg} / \mathrm{mL}$ and the elimination half-life was 16-20 hours. ${ }^{55}$ A randomized, partially blinded Phase IIa extended early bactericidal activity trial has been conducted in South Africa to evaluate the dose-response of PA-824 in newly diagnosed patients with smear-positive pulmonary tuberculosis. There was no dose-response observed over the 200-1200 mg dose range tested. ${ }^{56}$ While the lack of doseresponse for the 600-1200 $\mathrm{mg}$ doses may be explained by the abovementioned plateau in drug exposure, the lack of dose effect over the $200-600 \mathrm{mg}$ dose range is surprising. A second 14-day dose-ranging early bactericidal activity trial evaluating PA-824 doses of 50, 100, 150, and $200 \mathrm{mg}$ was completed in September 2010, but the results have not been published as yet.

\section{OPC-67683}

OPC-67683 is a dihydroimidazo-oxazole agent under development by Otsuka Pharmaceuticals specifically for the treatment of tuberculosis. Cross-resistance with PA-824 occurs through mutations in Ddn, the enzyme responsible for activation. ${ }^{57}$ OPC-67683 is more potent than PA-824 in vitro and in vivo, with a minimum inhibitory concentration of $0.006-0.024 \mathrm{mg} / \mathrm{mL}$ and minimum bactericidal activity at $2.5 \mathrm{mg} / \mathrm{kg}$ in mice, resulting in a $2 \log _{10}$ reduction in colony forming units, ${ }^{45}$ as compared with $50 \mathrm{mg} / \mathrm{kg}$ for PA-824 in a similar model by Nuremberger (unpublished observation). In a Phase I multidose investigation using two different formulations, OPC-67683 was administered in doses up to $400 \mathrm{mg}$. A 14-day extended early bactericidal activity trial has been performed with the newer formulation of OPC-67683, but the results have not been reported in detail. A Phase IIb trial has been completed in patients with multidrug-resistant tuberculosis randomized to receive 
an optimized background regimen with either OPC-67683 at 100 or $200 \mathrm{mg}$ twice daily or placebo in June 2010, with the first follow-up in October 2010, but no results have been reported thus far.

\section{Pyrroles}

The antituberculous activity of the pyrrole class was first described in 1998. The most potent of the compounds described at that time was BM212, with minimum inhibitory concentrations that ranged from 0.7 to $1.5 \mathrm{mg} / \mathrm{mL}$ against several strains of $M$. tuberculosis. The minimum inhibitory concentrations for resistant strains are similar to those for susceptible strains, suggesting a novel mechanism of action. ${ }^{58}$

LL-3858, also a pyrrole, was discovered in 2004. While the mechanism of action remains unknown, early reports described a minimum inhibitory concentration range of $0.06-0.5 \mathrm{mg} / \mathrm{mL}$ that was not affected by resistance to isoniazid and rifampicin. Additive activity in combination with firstline drugs in the murine model was also described ${ }^{59}$ LL3858 is being developed by Lupin and has been evaluated in a multidose Phase 1 trial involving healthy volunteers in India. An open-label Phase IIa trial to determine the early bactericidal, extended early bactericidal activity, and pharmacokinetics of LL-3858 for the treatment of newly diagnosed sputum smear-positive pulmonary tuberculosis has been completed, but the results are not available to the public. ${ }^{60}$

\section{Diamine}

SQ109, or N-adamantan-2-yl-N'-(3,7-dimethylocta-2,6dienyl)-ethane-1,2-diamine, is being developed by Sequella. Although originally intended to be an improvement on ethambutol, a first-line tuberculosis drug, its structural dissimilarity to ethambutol and the potential differences in its intracellular target(s) suggest that it may be a truly novel antimycobacterial agent and not an analog of ethambutol. It has a minimum inhibitory concentration of $0.16-0.64 \mathrm{mg} / \mathrm{mL}$, which does not appear to be affected by resistance to ethambutol. The mechanism of action of SQ109 remains to be fully elucidated. Inhibition of cell wall synthesis is implicated by the induction of Rv0341 but, in addition to the lack of evidence for cross-resistance, gene expression analysis suggests it may not be the same as seen with ethambutol. ${ }^{61,62}$

SQ109 is an orally active antibiotic for treatment of pulmonary tuberculosis, Helicobacter pylori-related duodenal ulcers and carcinomas, and Candida glabrata. ${ }^{63,64}$ Currently in Phase II clinical trials, SQ109 could replace one or more drugs in the current first-line tuberculosis drug regimen, simplify therapy, and shorten the treatment regimen..$^{63} \mathrm{~A}$ multidose escalation study has been completed. In vitro metabolism studies using recombinant cDNA expressed human CYPs in conjunction with specific CYP inhibitors, indicating that CYP2D6 and CYP2C19 were the predominant CYPs involved in SQ109 metabolism, with little effect of CYP3A $4 .{ }^{65}$

\section{Dipiperidines}

Dipiperidines comprise a series of compounds derived from a 25,000-compound library based on changing the ethylene bridge of 1,2 ethylenediamines. Many of these compounds contain a dipiperidine pharmacophore. Several compounds in the dipiperidine class demonstrated good activity against M. tuberculosis, low nonspecific cytotoxicity, a selectivity index indicative of a suitable therapeutic window, and good $\log \mathrm{P}$ values (an in silico predictor of intestinal absorption).

The dipiperidine hits included an adamantane-containing hydroxydipiperidine, SQ609, which has been demonstrated to be the most promising compound of this class. SQ609 is an orally active small-molecule antibiotic proposed for treatment of pulmonary tuberculosis and is currently entering preclinical safety, pharmacology, and toxicology studies as an investigational new drug. SQ609 is expected to increase the efficacy of the first-line drug regimen, simplify therapy, and/or shorten the treatment duration for drug-sensitive and drug-resistant tuberculosis. As per the statement by its developer, Sequella, SQ609 has unique characteristics that may give it the potential to be an important new tool in the treatment of both drug-sensitive tuberculosis, as well as multidrug-resistant and extensively drug-resistant tuberculosis.

A summary of its attributes includes:

- Potent in vitro activity against laboratory and clinical strains of M. tuberculosis

- Inhibition of M. tuberculosis by interfering with cell wall biosynthesis

- Moderate in vitro cytotoxicity in cultured mammalian cells

- A suitable therapeutic window in vitro

- Activity against intracellular M. tuberculosis

- Activity against single-drug resistant strains of M. tuberculosis (isoniazid, rifampin, and streptomycin)

- High specificity for M. tuberculosis

- Good aqueous solubility

- Oral activity by itself in two different mouse models of tuberculosis 
- Ability to prolong the therapeutic effect after withdrawal of single and multiple drugs during therapy in mice

- Activity better than tuberculosis standard of care (1-2 $\log _{10}$ ) when administered in combination with isoniazid, rifampin, and pyrazinamide in murine models of tuberculosis

- Favorable in vitro safety, pharmacology, and absorption, distribution, metabolism and excretion profile. ${ }^{66}$

\section{Capuramycins}

SQ641, a semisynthetic antibiotic, is the lead drug candidate selected from a 7000-compound library of semisynthetic nucleoside-based translocase 1 (TL-1) inhibitors developed as potential treatments for bacterial infections. It is particularly active against $M$. tuberculosis causing tuberculosis, nontuberculous mycobacterial pneumonia, pneumonia caused by Streptococcus pneumoniae, Crohn's disease, and Staphylococcus aureus, including the methicillinresistant strain that causes skin and soft tissue infections. The capuramycin class of antibacterial antibiotics inhibits the TL-1 enzyme which is essential for construction of the cell wall and is present only in bacteria. Because the TL-1 enzyme is absent in eukaryotic cells, it is an attractive target for antibiotic development. Despite the ubiquity of TL-1 in bacteria, capuramycin and its analogs, including SQ641, are remarkably specific for Mycobacteria and certain Gram-positive bacteria, making it a promising candidate for a future regime. Attributes of SQ641 as described by the developer (Sequella) ${ }^{67}$ include:

- Killing M. tuberculosis faster than any existing antituberculosis drugs, including isoniazid and rifampin

- Activity against all strains of multidrug-resistant clinical strains of $M$. tuberculosis tested to date

- An exceptional 55-hour post-antibiotic effect against M. tuberculosis

- Strong synergy with ethambutol, streptomycin, and SQ109 (the manufacturer's lead antituberculosis drug, currently completing Phase 1B clinical trials)

- Strong efficacy in preventing development of drug-resistant mutants of M. tuberculosis

- Excellent in vitro activity against nontuberculous Mycobacteria, ie, M. avium complex, M. abscessus, and $M$. kansasii, as well as the M. avium subspecies paratuberculosis, the etiologic agent of Johne's disease (and suspected etiologic agent of Crohn's disease),

- Synergism with a variety of agents having activity against nontuberculous Mycobacteria. ${ }^{67}$

\section{Isothiazoloquinolones}

Isothiazoloquinolones are an underexplored chemotype related to quinolones, first described by $\mathrm{Chu}$ et al and Abbott in the late 1980s. ${ }^{68,69}$ Isothiazoloquinolones have a substitution in the typical 3-carboxyl group by an isothiazolone ring and have demonstrated good antibacterial activity. $^{70,71}$

ACH-702 is a lead isothiazoloquinolone compound, the activity of which has been studied against a number of bacterial pathogens, including methicillin-resistant $S$. aureus (MRSA) and vancomycin-resistant Enterococcus, with promising results. ${ }^{70-72}$ Analogs of the quinolone class, these compounds target bacterial replication and are potent inhibitors of both DNA gyrase and topoisomerase IV. ${ }^{73}$

ACH-702 has a novel target profile against bacterial DNA replication enzymes and potent broad-spectrum bactericidal activity, characteristics which may play an important role in the fight against drug-resistant bacteria. ${ }^{74}$ Minimum inhibitory concentration assays of $\mathrm{ACH}-702$ against clinical isolates of $M$. tuberculosis, including drug-resistant isolates, and additional isolates of nontuberculous Mycobacteria, have shown comparable or superior activity to moxifloxacin in most cases. ${ }^{75} \mathrm{ACH}-702$ is also effective against fluoroquinolone-resistant isolates of $M$. tuberculosis, consistent with its antibacterial activity against fluoroquinolone-resistant isolates of other bacteria. ${ }^{76}$

\section{Caprazene nucleosides}

CPZEN-45 is a nucleoside antibiotic that is soluble in water at $>10 \mathrm{mg} / \mathrm{mL}$ as the trifluoroacetate salt. It is a caprazamycin produced by Streptomyces spp, and was first described in 2003 by researchers at the Microbial Chemistry Research Foundation and Meiji Seika Kaisa Ltd in Japan. CPZEN-45 has a minimum inhibitory concentration of $1.56 \mu \mathrm{g} / \mathrm{mL}$ against $M$. tuberculosis H37Rv and $6.25 \mu \mathrm{g} / \mathrm{mL}$ against a multidrug-resistant strain of $M$. tuberculosis. This compound is active against both replicating and nonreplicating $M$. tuberculosis in vitro, suggesting it could be efficacious against latent organisms in vivo. CPZEN-45 has shown efficacy against both drug-sensitive and extensively drug-resistant $M$. tuberculosis in a mouse model of acute tuberculosis, in which animals were infected by intravenous injection and treated with subcutaneous administration of CPZEN-45. Improved efficacy against drug-sensitive $M$. tuberculosis was shown when CPZEN-45 was administered in combination with other antituberculous drugs. ${ }^{77}$ 


\section{Benzothiozinones and dinitrobenzamide}

These agents were found to be highly active against resistant and sensitive strains of $M$. tuberculosis, including extensively drug-resistant and multidrug-resistant strains. Both BTZ043 (a benzothiozinone) and dinitrobenzamide drugs have the same target, ie, heterodimeric decaprenylphosphoryl-D-

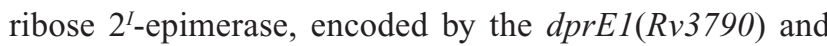
dprE2(Rv3791) genes, ${ }^{78}$ thereby blocking arabinogalactan and lipoarabinomannan synthesis in the mycobacterial cell wall and growth of M. tuberculosis. ${ }^{79}$

To monitor for potential development of benzothiazinone resistance, a total of 240 sensitive and multidrug-resistant M. tuberculosis clinical isolates from four European hospitals were surveyed for the presence of mutations in the $d p r E 1$ gene and for benzothiazinone susceptibility. All 240 strains were susceptible, thus establishing a baseline prior to the introduction of BTZ043 in clinical trials. ${ }^{80}$ The EPFL School of Life Sciences is the current developer of this drug that has now entered Phase I clinical investigation in humans.

\section{Imidazopyridine}

Q201 is a compound undergoing preclinical investigation at Quro Science in Korea as of 2010, and is expected to enter Phase I study by 2011, although no information about the drug has been made available to the public. ${ }^{81,82}$

\section{Riminophenazines}

Riminophenazines were discovered in the 1970s and were proposed as a probable solution to multidrug-resistant tuberculosis as early as $1999 .{ }^{83}$ They have been effective in treating leprosy, although existing compounds have poor solubility and side effects, such as pronounced skin discoloration. In 2007, the TB Alliance, in partnership with the Institute of Materia Medica in Beijing, designed and synthesized more efficacious compounds in this promising class.

Riminophenazines are thought to inhibit the energy metabolism needed even in slow-growing M. tuberculosis persisters, and therefore show promise for shortening the duration of treatment. They show no cross-resistance with any other class of antituberculous drugs, and are therefore potential agents for treating drug-resistant tuberculosis. Their lack of intrinsic CYP interactions would make them safe to coadminister with antiretrovirals in patients coinfected with tuberculosis and HIV ${ }^{84}$ Within the first year, the project team designed four series of molecules with pharmacophores which were distinct from that of clofazimine. These compounds were tested in vitro and in vivo for activity against M. tuberculosis and in various absorption, distribution, metabolism, elimination, and toxicity assays. Phenoxazine and an asymmetrical riminophenazine series showed both potent activity and improved physicochemical properties. ${ }^{84}$

\section{The Stop TB strategy}

As part of the millennium development goals, targets endorsed by the Stop TB Partnership had aimed to detect at least $70 \%$ of new sputum smear-positive tuberculosis cases and cure at least $85 \%$ of these cases by 2005 , to reduce tuberculosis prevalence and death rates by $50 \%$ relative to 1990 by 2015 , and to eliminate tuberculosis as a public health problem (less than one case per million population) by 2050 . Realizing the inadequacies of the program as evaluated in 2005, the Stop TB Strategy was devised by the WHO in 2006 with a vision of a world free of tuberculosis. The goal was to reduce the global burden of tuberculosis by 2015 dramatically, in keeping with the previously set targets. The objectives are to achieve universal access to high-quality diagnosis and patient-centered treatment, to reduce the suffering and socioeconomic burden associated with tuberculosis, to protect poor and vulnerable populations from the disease, coinfection with tuberculosis and HIV, and multidrug-resistant tuberculosis, as well as to support development of new tools and enable their timely and effective use. One important component of the program is to promote research to develop new drugs, vaccines (Table 2), and diagnostics (Table 3 ). ${ }^{85}$

Table 2 TB vaccine constructs in phase II clinical trials (as of July 20II)

\begin{tabular}{lllll}
\hline Agent & Strategy & Type & Sponsors & Status \\
\hline MVA85A/ & Prime boost & Viral vector & Oxford-Emergent & Phase Ilb \\
$\begin{array}{l}\text { AERAS-485 } \\
\text { AERAS-402/ }\end{array}$ & Prime boost & Viral vector & Tuberculosis Consortium, Aeras & Phase Ilb \\
$\begin{array}{l}\text { Crucell Ad35 } \\
\text { GSKM72 }\end{array}$ & Prime boost & Crucell N.V., Aeras & \\
RUTI & Immunotherapeutic & Recombinant protein & GSK Biologicals, Aeras & Phase II \\
\hline
\end{tabular}

Note: Reproduced with permission from the Treatment Action Group (http://www.treatmentactiongroup.org/pipeline-report/20I I).

Abbreviations: GSK, GlaxoSmithKline; MTB, Mycobacterium tuberculosis. 
Table 3 TB Diagnostic Test or Processes in the Pipeline, 20II

\begin{tabular}{|c|c|c|c|c|}
\hline Name of test & Sponsor/Developer & Technique & What it measures & $\begin{array}{l}\text { Estimated date } \\
\text { of WHO review }\end{array}$ \\
\hline \multicolumn{5}{|l|}{ Peripheral laboratories } \\
\hline $\begin{array}{l}\text { Manual loop-mediated } \\
\text { isothermal amplification } \\
\text { process (LAMP) }\end{array}$ & $\begin{array}{l}\text { Eiken Chemical/Foundation } \\
\text { for Innovative New } \\
\text { Diagnostics (FIND) }\end{array}$ & Manual nucleic acid amplification & MTB DNA & 2012 \\
\hline Clearview $^{\circledR}$ TB ELISA & Alere & $\begin{array}{l}\text { ELISA to detect Lipoarabinomannan } \\
(\text { LAM) in urine }\end{array}$ & MTB LAM antigen & 2013 \\
\hline $\begin{array}{l}\text { Colorimetric Thin } \\
\text { Layer Agar (TLA) DST }\end{array}$ & $\begin{array}{l}\text { London School of Hygiene } \\
\text { and Tropical Medicine/ } \\
\text { FIND }\end{array}$ & $\begin{array}{l}\text { Colorimetric DST by culturing } \\
\text { TB on a TLA plate and using } \\
\text { microscopy to identify MTB growth }\end{array}$ & MTB culture growth & 2012 \\
\hline \multicolumn{5}{|l|}{ Reference laboratories } \\
\hline GenoType ${ }^{\circledR}$ MTBDRs & Hain Lifescience/FIND & $\begin{array}{l}\text { Line probe assay to identify drug } \\
\text { susceptibility to second-line TB } \\
\text { drugs on TB culture isolate; is } \\
\text { being tested on sputum samples }\end{array}$ & $\begin{array}{l}\text { MTB DNA indicating resistance } \\
\text { to fluoroquinolones, ethambutol, } \\
\text { and aminoglycosides/cyclic } \\
\text { peptides (amikcin, kanamycin, } \\
\text { capreomycin) }\end{array}$ & 2012 \\
\hline $\begin{array}{l}\text { Sensititre }{ }^{\circledR} \text { MTB } \\
\text { minimum inhibitory } \\
\text { concentration } \\
\text { (MIC) Plate }\end{array}$ & TREK Diagnostic Systems & $\begin{array}{l}\text { Detects MTB growth in TB } \\
\text { antibiotic containing plates to } \\
\text { identify drug resistance }\end{array}$ & TB bacilli & 2013 \\
\hline
\end{tabular}

Note: Reproduced with permission from the Treatment Action Group (http://www.treatmentactiongroup.org/pipeline-report/20I I).

Abbreviations: DST, drug susceptibility testing; ELISA, enzyme linked immunosorbent assay; DNA, deoxyribonucleic acid; TB, tuberculosis; MTB, Mycobacterium tuberculosis.

\section{Tuberculosis vaccination in the pipeline}

The existing tuberculosis vaccine, Bacille Calmette-Guérin (BCG), is only partially effective and is contraindicated in HIV coinfection. A novel tuberculosis vaccine or regimen is a key component of the Stop TB Strategy. Target populations for a tuberculosis vaccine are adults, adolescents, children, and infants in high-burden countries, including individuals with HIV coinfection or latent tuberculosis infection. Ongoing clinical trials of BCG are evaluating modifications to the current vaccination methods. Prophylactic tuberculosis vaccines in clinical trials are live mycobacterial vaccines designed to replace the BCG or subunit vaccines designed to boost BCG. ${ }^{86}$

Current tuberculosis vaccine candidates are designed to contain the tuberculosis bacillus by enabling the immune system to get a "head start" when exposed, reducing the bacterial load and preventing progression to clinical disease, ${ }^{87,88}$ without inducing sterilizing immunity or, in other words, to prevent infection altogether. Clinical development of a new tuberculosis vaccine is dependent upon validation in animal models of safety, toxicology, and efficacy, and the identification of biomarkers of protection. The most advanced candidate vaccines are currently in Phase IIb trials. Field sites in high-burden countries are required for large-scale efficacy and licensure trials. ${ }^{86}$
M72 is a recombinant protein vaccine made up of an adjuvant molecule that stimulates an immune response, and two recombinant tuberculosis proteins intended to strengthen the immune response to two highly immunogenic fragments of the tuberculosis bacillus. Early results suggest that the vaccine is clinically well tolerated and produces a measurable immune response. ${ }^{89}$ Subsequent clinical trials are now planned for adolescents and infants in tuberculosis-endemic regions. ${ }^{90}$

AERAS-402/Crucell Ad35 from Crucell NV and Aeras is an adenovirus 35 (Ad35) modified to include specific tuberculosis antigens to trigger an immune response. A series of Phase I studies has demonstrated tuberculosis-specific CD4 and $\mathrm{CD} 8$ responses in BCG-naive and BCG-vaccinated adult volunteers after receiving the vaccine. A Phase II clinical trial in adults recently treated for pulmonary tuberculosis and a Phase I study in infants are ongoing. A Phase IIb randomized, placebo-controlled, proof-of-concept study in HIV-positive adults with CD4 counts $>350$ was recently initiated to evaluate the safety and efficacy of AERAS-402/ Crucell Ad35. ${ }^{89}$

MVA85A/AERAS-485 is a live viral-vectored vaccine that is an attenuated version of the vaccinia virus combined with tuberculosis antigen $85 \mathrm{~A}$. The first infant received a dose in July 2009 as part of a Phase IIb proof-of-concept study. This is the first time in over 80 years that a vaccine has 
been tested for efficacy in infants. ${ }^{91}$ The trial is comparing MVA85A versus placebo in BCG-vaccinated, HIV-negative infants. The first results are expected in $2012 .{ }^{86}$ RUTI is a killed TB vaccine that was originally discovered at Institut Germans Trias i Pujol and is now being developed by the biotech company Archivel Farma. The vaccine is being evaluated for its potential to accelerate the treatment of latent TB infection in combination with isoniazid. It has a potential for reducing risk of isoniazid resistance by shortening the duration of therapy. ${ }^{92}$ Seven more candidates are being tested clinically in a Phase I trial including recombinant live and other types of vaccines and one Mycobacterium vaccaeinactivated whole cell nontuberculous mycobacterial vaccine has undergone Phase III investigation. There are six candidates undergoing preclinical studies, and 22 next-generation candidates are being developed. ${ }^{92}$

\section{Diagnostic pipeline for tuberculosis}

Despite significant progress at a level suitable for reference or peripheral laboratories, investment in the research necessary to discover and develop a true point-of-care test for tuberculosis is shockingly inadequate. There is no peer-reviewed information available about a diagnostic tool that is likely to be approved by the Who Strategic and Technical Advisory Group for Tuberculosis in the next three years for use at the health post. ${ }^{93}$ The Eiken loop-mediated isothermal amplification process (LAMP) nucleic acid test and Clearview lipoarabinomannan antigen enzyme-linked immunosorbent assay test could be performed in peripheral laboratories. Lower sensitivity of sputum-negative cases in the LAMP test and in patients with HIV coinfection and a CD4 count $>200$ in a lipoarabinomannan enzyme-linked immunosorbent assay test have led to uncertainty about the significance of these noninvasive and relatively rapid tests.

GeneXpert MTB/RIF, a reference laboratory test, is highly sensitive as well as specific in smear-positive cases and could also identify rifampicin-resistant strains. The test requires minimal training of laboratory workers and provides results within 2 hours. Because it is a closed-system test, it does not require laboratories with high levels of biosafety and has low contamination concerns. However, the prohibitive costs of the kit and instruments are an impediment to its widespread application. ${ }^{94}$

\section{Interferon-gamma release assays}

The three interferon-gamma release assays available on the market are the QUANTIFeron Gold test (QFT-G) and QUANTIFeron Gold in a Tube test (QFT-GIT), both produced by Cellestis (Valencia, CA), and T-SPOT.TB from Oxford Immunotec (Marlborough, MA). These tests are immune-based tests for latent tuberculosis infection. BCG vaccination does not cause false positives in the interferon-gamma release assay, as is often the case with the tuberculin skin test. The first and second tests require samples to be processed within 16 hours on an enzyme-linked immunosorbent assay format, which prevents them from being used in health facilities at levels below reference laboratories. The tests have moderate sensitivity. The third tuberculosis test (T-SPOT) requires that the sample be processed in 8 hours and needs a greater degree of sample processing. ${ }^{94}$

The diagnostic pipeline for tuberculosis has yielded a group of new tools that have addressed important gaps in the current armamentarium, although they have not yet translated into any significant measurable improvement in tuberculosis case detection or treatment outcomes, mainly because they are not appropriate for peripheral health post settings in low-income countries where most people with tuberculosis access their care..$^{95}$

Improved diagnostics and incorporation of potent bactericidal as well as sterilizing agents into antituberculous regimens should make the prognosis of multidrug-resistant and extensively drug-resistant tuberculosis much better, and emergence of new multidrug-resistant or extensively drug-resistant strains a rarity, at least in theory. However, keeping in mind the failure of conventional first-line drugs that theoretically should have been effective in $95 \%$ of cases, other regulatory and administrative challenges, economic constraints leading to suboptimal therapy, uncontrolled drug usage in the private sector allowing unscientific combinations and undertreatment facilitating emergence of resistant strains, and irresponsible overtreatment or retreatment, must also be addressed. After investing billions of dollars in drugs, lack of control over implementation of ideal and adequate regimens and irresponsible usage in the private sector, which has a $60 \%$ share of the world antituberculous drug market, would pose a risk of losing these drugs to resistance quickly, without exploiting their full potential to achieve the goals of the Stop TB program. ${ }^{96}$

Strategies to develop new antituberculous drugs include screening libraries of small molecules and natural products, as well as prior identification of targets crucial to the micro-organism and subsequent design of new molecules. Development of new drugs from known compounds which have already shown safety and efficacy is an attractive strategy from the economical, pharmaceutical, and clinical points of view. ${ }^{95}$ 


\section{Innovative approaches}

Kinnings et al developed a chemical systems approach to identify off-targets of major pharmaceuticals on a proteome-wide scale and showed that entacapone and tolcapone, presently used in the treatment of Parkinson's disease, have the potential to treat multidrug-resistant and extensively drug-resistant tuberculosis. ${ }^{97}$ These drugs are predicted to bind to the InhA enzyme and directly inhibit substrate binding. The minimum inhibitory concentration of entacapone for $M$. tuberculosis is approximately $260.0 \mu \mathrm{M},{ }^{99}$ which is well below the toxicity concentration determined by an in vitro cytotoxicity model using a human neuroblastoma cell line. Thus, the active component in entacapone represents a promising lead compound for developing a new class of antituberculous therapeutics with an excellent safety profile, and incorporating a similar approach might discover novel drugs with a similar safety profile. ${ }^{97}$

\section{Thioridazine}

Thioridazine, a known phenothiazine neuroleptic, has been shown to modulate the expression of genes encoding membrane proteins and efflux pumps, as well as oxidoreductases and other enzymes involved in fatty acid metabolism and aerobic respiration..$^{98}$ Because thioridazine targets multiple pathways, including those involved in cell wall processes and respiratory chain components, it may serve as a model for multitarget drug development, as well as constitute a highly potent addition to a combination of antituberculous drug regimens for the management of multidrug-resistant and extensively drug-resistant disease. ${ }^{99}$ Thioridazine was used to cure 10 of 12 patients with extensively drug-resistant tuberculosis in Buenos Aires, Argentina. It is being used for compassionate treatment of terminal patients with extensively drug-resistant tuberculosis nonresponsive to antibiotics in Mumbai, India. ${ }^{100}$

\section{Capreomycin}

Capreomycin, an ideal second-line drug for multidrugresistant tuberculosis, has seen a setback with the emergence of capreomycin-resistant cases due to single gene mutations in Mycobacteria. Detailed characterization of capreomycin targets by data mining was undertaken to construct an interaction topology of the M. tuberculosis genes responsive to capreomycin. Integrating genes, small metabolites, proteins, and underlying signaling pathways to shed light on the physiology, pathogenesis, and network of pathogen responses have been emerging, and show great promise for unravelling the intricate drug action involved. Dampening of virulence factors and the aerobic respiratory rate of $M$. tuberculosis might be the new targets of capreomycin beyond Rv1364c, pe_pgrs38, and pe_pgrs51, which are the salient nodes of the network and thus the most promising new capreomycin targets meriting further exploration. ${ }^{101}$

\section{Fosmidomycin}

2C-methyl-d-erythritol 4-phosphate (MEP) lacks homologous enzymes in the human host, so is a vital pathway in M. tuberculosis, is amenable to bacterium-specific drug targeting, and shows potential for identification of lead compounds unencumbered by target-based toxicity. Fosmidomycin is now known to inhibit the second step in the MEP pathway. High-throughput screening campaigns in the search for new compounds that manipulate enzymes of the MEP pathway may discover molecules effective against multidrug-resistant and extensively drug-resistant tuberculosis. ${ }^{102}$

\section{Guanosine triphosphatases}

Guanosine triphosphatases have been noted to have a crucial role in the survival and pathogenesis of various pathogens by interference in the arrest of phagosome maturation, enabling pathogens to survive by escaping from lysozymes and toxic free radicals, enabling M. tuberculosis to evade the host defense system, which contributes to its virulence. This observation provides a new avenue for the development of antituberculous drugs. ${ }^{103}$

Antituberculous compounds from natural sources have an enormous potential for new drug development. Some of these have demonstrated not only antimicrobial activity per se but also inhibition of the mechanism of resistance (eg, efflux pumps) or modulation of the immune response (eg, macrophage stimulation). ${ }^{96}$

\section{Herbal agents}

Dihydro- $\beta$-agarofuran sesquiterpene, $(1 \alpha$-acetoxy- $6 \beta, 9 \beta$ dibenzoyloxy-dihydro- $\beta$-agarofuran) isolated from Celastrus vulcanicola exhibited antituberculous activity against the multidrug-resistant tuberculosis strain with a minimum inhibitory concentration of $6.2 \mu \mathrm{g} / \mathrm{mL}$, comparable with or better than that for isoniazid or rifampin, which are two of the best first-line drugs commonly used to treat tuberculosis. ${ }^{104}$

Aristolochia taliscana is a plant used in traditional Mexican medicine to treat cough and snake bites. Bioguided fractionation of hexanic extract led to the isolation of neolignans licarin A, licarin B, and eupomatenoid-7, all of 
which have antimycobacterial activity. Licarin A was the most active compound, with a minimum inhibitory concentration of 3.12-12.5 $\mu \mathrm{g} / \mathrm{mL}$ against several M. tuberculosis strains, including H37Rv, four monoresistant $\mathrm{H} 37 \mathrm{Rv}$ variants, and 12 clinical multidrug-resistant isolates, as well as five nontuberculous mycobacterial strains. ${ }^{105}$

Essential oils of Myrtus communis L. are gaining remarkable interest for their potential multipurpose use as antioxidant, antibacterial, and antiseptic agents, and have been used in the past for the treatment of other lung diseases. The results for myrtle oil show good activity against $M$. tuberculosis but not against $M$. paratuberculosis. The minimum inhibitory concentration registered against M. tuberculosis was $0.17 \%(\mathrm{v} / \mathrm{v})$ in comparison with a minimum inhibitory concentration of $2 \%(\mathrm{v} / \mathrm{v})$ observed against $M$. paratuberculosis. ${ }^{106}$

Crude extracts of Aloe vera, Adhatoda vasica, and Allium sativum against multidrug-resistant isolates confirm earlier results, and activity of extracts of Acalypha indica and Allium cepa has been reported for the first time. Further studies aimed at isolation and identification of active substances from extracts showing promising activity now need to be carried out. ${ }^{107}$

Curcuma longa and Tinospora cordifolia formulations have been used as an adjuvant to conventional antituberculous treatment to prevent hepatotoxicity as well as to study their effects on the course of complicated tuberculosis. In multidrug-resistant nonresponders to DOT therapy, an extended course of first-line antituberculous treatment and herbs achieved a good clinical, radiological, and bacteriological response in $68 \%$ of cases. ${ }^{108}$

\section{Surgical measures}

It is surprising that surgical measures as an option or possibility for multidrug-resistant and extensively drug-resistant tuberculosis treatment have never been incorporated in strategic planning by any responsible body. However, promise of a cure in hopeless cases is not altogether absent in the peer-reviewed literature. Careful patient selection with adequate preoperative evaluation, ie, localized cavitating disease involving extensively drug-resistant or totally drug-resistant strains, and documented failure of optimal medical therapy, could ensure a superior outcome using an appropriate surgical resection procedure, although there is considerable risk of early postoperative morbidity. ${ }^{109-111}$ In view of recent evidence showing that the risk of primary infection with multidrug-resistant or extensively drugresistant $M$. tuberculosis strains is growing, the surgical option looks to be attractive in carefully selected patients, where the median time to postoperative sputum smear and culture conversion has been reported to be 2 (range 1-23) days. ${ }^{109}$

\section{Novel drug delivery systems}

The use of liposomes, polymeric microparticles, and nanoparticles as inhalable antituberculous drug carriers has been investigated. ${ }^{112}$ Nanoparticles in particular have emerged as a remarkably useful tool for this purpose due to their high stability, feasibility of incorporation of both hydrophilic and hydrophobic substances, and ease of oral and inhalational administration in addition to parenteral administration. Nanoparticles may also be useful to deliver drugs selectively to monocytes, macrophages, or the reticuloendothelial system, where dormant persistent organisms responsible for lengthy treatment periods may be lodging. ${ }^{15}$

Dry powder inhalers and nebulizers are another approach being tested. ${ }^{112}$ Dry porous particle aerosols of PA-824 have been tested in low and high (eight-fold higher than the oral dose) dosages and compared with oral administration of PA-824 for treatment of tuberculosis in guinea pigs. The results show a lower degree of inflammation, bacterial load, and tissue damage, suggesting a potential role for these inhalational agents in the treatment of tuberculosis. ${ }^{113}$ Capreomycin, a second-line drug, is being tested as an inhalational product in the form of large porous particles administered to human volunteers in a Phase I study. Inhalational approaches deliver much higher doses of drug to the lung, but the exact histological localization of the increased delivery is not clear. ${ }^{15}$ Cost of goods and training of health care providers and patients in efficient usage and prevention of cross-infection by instruments are the main obstacles to wider application, compounded by ambiguous evidence of superior efficacy for such a regimen.

\section{Predictive biomarkers}

In the absence of reliable biomarkers, we need to continue performing large and lengthy Phase III trials with 12-24 months of follow-up after treatment for cure or relapse, which is a real obstacle to devising novel regimens with newer drugs in various combinations for multidrug-resistant or extensively drug-resistant tuberculosis. A predictive biomarker could greatly reduce the duration and number of patients needed in trials and hasten the development of new tuberculosis regimens. ${ }^{4}$ A reliable biomarker would be able to assess the activity and extent of disease, response to treatment, treatment outcome (cure or relapse), anticipated poor clinical 
outcomes (so that treatment can be modified appropriately), and endpoints of novel antituberculous drugs. ${ }^{114}$ Currently the WHO and the European Commission have undertaken a joint biomarker study, and their report published in 2008 has recommended further research on microbiological markers like microbiological load, quantitative sputum microbiology study, mycobacterial antigens 85 and $85 \mathrm{~B}$, mycobacterial DNA fragments, lipoarabinomannan and other protein antigens in urine, and volatile mycobacterial markers in breath. Host markers involve interferon-gamma release assays, antibodies to mycobacterial enzymes, and $38 \mathrm{kDa}$ antigen, interferon gamma measured in sputum, soluble intercellular adhesion molecule type 1, neopterin (catabolic product of guanosine triphosphate), erythrocyte sedimentation rate, C-reactive protein, soluble urokinase plasminogen activator receptor (mainly expressed by macrophages and monocytes), host proteins like LAG-3V3, sCD30, total Ig E, chemokine CCL22, the IL-4/IL-4 22 ratio, and whole blood killing assays.

Advanced technological platforms like transcriptomics, proteomics, and metabolomics have been envisaged for future development of ideal biomarkers, although analysis and integration of data from transcriptomic, proteomic, and metabolomic investigations would be required to understand the "bigger picture" of the response and outcome of antituberculous treatment. Highly skilled bioinformaticists would be required to interpret the enormously complex data sets before the results could be put into a biological context. ${ }^{114}$

\section{The Critical Path to New TB Regimens}

In the absence of surrogate markers, the conventional approach to drug combination development evaluates potential compounds sequentially, substituting them individually into the existing regimen. Each alteration is studied in clinical trials, which take at least six years to complete, so any regimen of new drugs would require at least 24 years of development. To overcome this challenge, the TB Alliance is promoting a new paradigm for tuberculosis drug development, known as the Critical Path to New TB Regimens. Under this new approach, each potential drug compound would be assessed individually in Phase I and early bacterial activity trials. At the same time, potential combinations would be evaluated in preclinical models. This would first involve identifying the potential for any two agents to have synergistic and antagonistic effects against $M$. tuberculosis in vitro, under both replicating and nonreplicating conditions, in the laboratory. Potential drug combinations would then be evaluated in vivo for potential pharmacokinetic interactions, and prioritized for efficacy studies in mice. Promising combinations with significant efficacy would be further evaluated for their sterilizing activity. When up to five combinations have been identified with the potential for shortening therapy to less than 3 months, the two or three most effective combinations would be confirmed in a secondary animal infection model. The most effective new regimens would then be moved into human Phase I trials for pharmacokinetic interaction and safety studies in healthy volunteers, followed by Phase II and III trials that may shorten the regimen development time to around 6 years. ${ }^{115}$

\section{Conclusion}

Emerging options including novel regimens developed from the antituberculous drug pipeline, rapid diagnostic tools, and before and after exposure vaccines for tuberculosis will fail to make a significant impact if they are not accompanied by proper support from local health care systems, both public and private, as well as control measures from governmental authorities. Ensuring proper access to these tests, vaccines, and new drug regimens by patients most in need in resourcepoor countries should be taken up as a challenge by the WHO, as well as the international health care community, to achieve the desired outcome.

\section{Disclosure}

The authors have no potential conflicts of interest to report in relation to this paper.

\section{References}

1. World Health Organization. 2010/2011 Tuberculosis Global Facts [Internet]. Geneva: World Health Organization; Nov 2010. Available from: http://www.who.int/tb/publications/2010/factsheet_tb_2010.pdf. Accessed 4 Nov, 2011.

2. World Health Organization. Multidrug and extensively drug resistant TB (M/XDR TB). Global Report on surveillance and response. 2010. Available from: http://www.who.int/tb/publications/2010/978924599191/ en/index.html. Accessed September 14, 2011.

3. Abu-Raddad LJ, Sabatelli L, Achterberg JT, et al. Epidemiological benefits of more-effective tuberculosis vaccines, drugs, and diagnostics. Proc Natl Acad Sci U SA. 2009;106:13980-13985.

4. Ma Z, Lienhardt C, McIlleron H, Nunn AJ, Wang X. Global tuberculosis drug development pipeline: the need and the reality. Lancet. 2010;375:2100-2109.

5. Gandhi NR, Nunn P, Dheda K, et al. Multidrug-resistant and extensively drug-resistant tuberculosis: a threat to global control of tuberculosis. Lancet. 2010;375:1830-1843.

6. Orenstein EW, Basu S, Shah NS, et al. Treatment outcomes among patients with multidrug-resistant tuberculosis: systematic review and meta-analysis. Lancet Infect Dis. 2009;9:153-161.

7. World Health Organization. Global tuberculosis control - epidemiology, strategy, financing. Global tuberculosis control: a short update to the 2009 report. Geneva, Switzerland: World Health Organization; 2009 
8. Velayati AA, Masjedi MR, Farnia P, et al. Emergence of new forms of totally drug-resistant tuberculosis bacilli: super extensively drugresistant tuberculosis or totally drug-resistant strains in Iran. Chest. 2009; $136: 420-425$.

9. Ginsberg AM. Emerging drugs for active tuberculosis. Semin Respir Crit Care Med. 2008;29:552-559.

10. Lienhardt C, Vernon A, Raviglione MC. New drugs and new regimens for the treatment of tuberculosis: review of the drug development pipeline and implications for national programmes. Curr Opin Pulm Med. 2010;16:186-193.

11. Mitscher LA. Bacterial topoisomerase inhibitors: quinolone and pyridone antibacterial agents. Chem Rev. 2005;105:559-592.

12. Moadebi S, Harder CK, Fitzgerald MJ, et al. Fluoroquinolones for the treatment of pulmonary tuberculosis. Drugs. 2007;67:2077-2099.

13. Rodriguez JC, Ruiz M, Climent A, et al. In vitro activity of four fluoroquinolones against Mycobacterium tuberculosis. Int $J$ Antimicrob Agents. 2001;17:229-231.

14. Rustomjee R, Lienhardt C, Kanyok T, et al; Gatifloxacin for TB (OFLOTUB) Study Team. A Phase II study of the sterilising activities of ofloxacin, gatifloxacin and moxifloxacin in pulmonary tuberculosis. Int J Tuberc Lung Dis. 2008;12:128-138.

15. Nuermberger EL, Spigelman MK, Yew WW. Current development and future prospects in chemotherapy of tuberculosis. Respirology. 2010;15:764-778

16. Mehlhorn AJ, Brown DA. Safety concerns with fluoroquinolones. Ann Pharmacother. 2007;41:1859-1866.

17. Burman WJ, Goldberg S, Johnson JL, et al. Moxifloxacin versus ethambutol in the first 2 months of treatment for pulmonary tuberculosis Am J Respir Crit Care Med. 2006;174:331-338.

18. Conde MB, Efron A, Loredo C, et al. Moxifloxacin versus ethambutol in the initial treatment of tuberculosis: a double-blind, randomised, controlled phase II trial. Lancet. 2009;373:1183-1189.

19. Dorman SE, Johnson JL, Goldberg S, et al. Tuberculosis Trials Consortium. Substitution of moxifloxacin for isoniazid during intensive phase treatment of pulmonary tuberculosis. Am J Respir Crit Care Med. 2009; 180:273-280.

20. Ma Z, Ginsburg AM, Spigelman M. Antibacterial: antimycobacterial agents. In: Taylor JB, Triggle D, editors. Comprehensive Medicinal Chemistry II. Oxford, UK: Elsevier; 2007.

21. Diekema DJ, Jones RN. Oxazolidinone antibiotics. Lancet. 2001;358: 1975-1982.

22. Zurenko GE, Yagi BH, Schaadt RD, et al. In vitro activities of U-100592 and U-100766, novel oxazolidinone antibacterial agents. Antimicrob Agents Chemother. 1996;40:839-845.

23. Williams KN, Stover CK, Zhu T, et al. Promising antituberculosis activity of the oxazolidinone PNU-100480 relative to that of linezolid in a murine model. Antimicrob Agents Chemother. 2009;53: 1314-1319.

24. Condos R, Hadgiangelis N, Leibert E, et al. Case series report of a linezolid-containing regimen for extensively drug-resistant tuberculosis. Chest. 2008;134:187-192.

25. Anger HA, Dworkin F, Sharma S, et al. Linezolid use for treatment of multidrug-resistant and extensively drug-resistant tuberculosis, New York City, 2000-06. J Antimicrob Chemother. 2010;65:775-783.

26. Ntziora F, Falagas ME. Linezolid for the treatment of patients with mycobacterial infections, a systematic review. Int J Tuberc Lung Dis. 2007;11:606-611.

27. Koh WJ, Kwon OJ, Gwak H, et al. Daily $300 \mathrm{mg}$ dose of linezolid for the treatment of intractable multidrug-resistant and extensively drugresistant tuberculosis. J Antimicrob Chemother. 2009;64:388-391.

28. Wallis RS, Jakubiec WM, Kumar V, et al. Pharmacokinetics and whole-blood bactericidal activity against Mycobacterium tuberculosis of single doses of PNU-100480 in healthy volunteers. J Infect Dis. 2010;202:745-751.

29. Cynamon MH, Klemens SP, Sharpe CA, et al. Activities of several novel oxazolidinones against Mycobacterium tuberculosis in a murine model. Antimicrob Agents Chemother. 1999;43:1189-1191.
30. Williams KN, Stover CK, Zhu T, et al. Promising antituberculosis activity of the oxazolidinone PNU-100480 relative to that of linezolid in a murine model. Antimicrob Agents Chemother. 2009;53: 1314-1319.

31. Williams KN, Brickner SJ, Stover CK, et al. Addition of PNU-100480 to first-line drugs shortens the time needed to cure murine tuberculosis. Am J Respir Crit Care Med. 2009;180:371-376.

32. Grosset J. Bacteriologic basis of short-course chemotherapy for tuberculosis. Clin Chest Med. 1980;1:231-241.

33. Mitchison DA. Role of individual drugs in the chemotherapy of tuberculosis. Int J Tuberc Lung Dis. 2000;4:796-806.

34. Heifets LB, Lindholm-Levy PJ, Flory MA. Bactericidal activity in vitro of various rifamycins against Mycobacterium avium and Mycobacterium tuberculosis. Am Rev Respir Dis. 1990;141: 626-630.

35. Keung A, Eller MG, McKenzie KA, et al. Single and multiple dose pharmacokinetics of rifapentine in man: Part II. Int J Tuberc Lung Dis. 1999;3:437-444

36. Langdon G, Wilkins JJ, Smith PJ, et al. Consecutive-dose pharmacokinetics of rifapentine in patients diagnosed with pulmonary tuberculosis Int J Tuberc Lung Dis. 2004;8:862-867.

37. Zhang M, Almeida D, et al. Isoniazid or moxifloxacin in rifapentinebased regimens for experimental tuberculosis? Am J Respir Crit Care Med. 2008;178:989-993.

38. Rosenthal IM, Williams K, Tyagi S, et al. Potent twice-weekly rifapentine-containing regimens in murine tuberculosis. Am J Respir Crit Care Med. 2006;174:94-101.

39. Lenaerts AM, Chase SE, Chmielewski AJ, Cynamon MH. Evaluation of rifapentine in long-term treatment regimens for tuberculosis in mice. Antimicrob Agents Chemother. 1999;43:2356-2360.

40. Gao XF, Li J, Yang ZW, Li YP. Rifapentine vs rifampicin for the treatment of pulmonary tuberculosis: a systematic review. Int JTuberc Lung Dis. 2009;13:810-819.

41. Diacon AH, Pym A, Grobudch M, et al. The diarylquinolone TMC207 for multi-drug-resistant tuberculosis. N Engl J Med. 2009;360:2397-2405.

42. European Medicines Agency. European Medicines Agency Decision P/55252/2011. Available at: http://www.ema.europa.eu/docs/ en_GB/document_library/PIP_decision/WC500105081.pdf. Accessed July 9,2011

43. Spigelman MK. Current and future therapeutic options for tuberculosis. Presentation 2190 at the 45th American Society for Microbiology Interscience Conference on Antimicrobial Agents and Chemotherapy. Washington, DC, December 16-19, 2005.

44. Ashtekar DR, Costa-Perira R, Nagrajan $\mathrm{K}$, et al. In vitro and in vivo activities of the nitroimidazole CGI 17341 against Mycobacterium tuberculosis. Antimicrob Agents Chemother. 1993;37:183-186.

45. Matsumoto M, Hashizume H, Tomishige T, et al. OPC-67683, a nitro-dihydro-imidazooxazole derivative with promising action against tuberculosis in vitro and in mice. PLoS Med. 2006;3:2131-2144.

46. Stover CK, Warrener P, VanDevanter DR, et al. A small-molecule nitroimidazopyran drug candidate for the treatment of tuberculosis. Nature. 2000;405:962-966.

47. Singh R, Manjunatha U, Boshoff HI, et al. PA-824 kills non-replicating Mycobacterium tuberculosis by intracellular NO release. Science. 2008;322:1392-1395.

48. Manjunatha UH, Boshoff $\mathrm{H}$, Dowd $\mathrm{CS}$, et al. Identification of a nitroimidazo-oxazine-specific protein involved in PA-824 resistance in Mycobacterium tuberculosis. Proc Natl Acad Sci U S A. 2006;103: 431-436.

49. Lenaerts AJ, Gruppo V, Marietta KS, et al. Preclinical testing of the nitroimidazopyran PA-824 for activity against Mycobacterium tuberculosis in a series of in vitro and in vivo models. Antimicrob Agents Chemother. 2005;49:2294-2301.

50. Hu Y, Coates AR, Mitchison DA. Comparison of the sterilizing activities of the nitroimidazopyran PA-824 and moxifloxacin against persisting Mycobacterium tuberculosis. Int J Tuberc Lung Dis. 2008;12: 69-73. 
51. Tyagi S, Nuermberger E, Yoshimatsu T, et al. Bactericidal activity of the nitroimidazopyran PA-824 in a murine model of tuberculosis. Antimicrob Agents Chemother. 2005;49:2289-2293.

52. Nuermberger E, Rosenthal I, Tyagi S, et al. Combination chemotherapy with the nitroimidazopyran PA-824 and first-line drugs in a murine model of tuberculosis. Antimicrob Agents Chemother. 2006;50:2621-2625.

53. Tasneen R, Tyagi S, Williams K, et al. Enhanced bactericidal activity of rifampin and/or pyrazinamide when combined with PA-824 in a murine model of tuberculosis. Antimicrob Agents Chemother. 2008;52:3664-3668.

54. Nuermberger E, Tyagi S, Tasneen R, et al. Powerful bactericidal and sterilizing activity of a regimen containing PA-824, moxifloxacin, and pyrazinamide in a murine model of tuberculosis. Antimicrob Agents Chemother. 2008;52:1522-1524.

55. Ginsberg AM, Laurenzi MW, Rouse DJ, et al. Safety, tolerability, and pharmacokinetics of PA-824 in healthy subjects. Antimicrob Agents Chemother. 2009;53:3720-3725.

56. Ginsberg A, Diacon A, Dawson R, et al. Extended early bactericidal activity (EBA) of PA-824, a novel drug for tuberculosis treatment. Final Program of the 48th Annual Interscience Conference on Antimicrobial Agents and Chemotherapy and the Infectious Diseases Society of America 46th Annual Meeting, Washington, DC, October 25-28, 2008.

57. [No authors listed]. OPC-67683. Tuberculosis (Edinb.) 2008;88: 132-133.

58. Deidda D, Lampis G, Fioravanti R, et al. Bactericidal activities of the pyrrole derivative BM212 against multidrug-resistant and intramacrophagic Mycobacterium tuberculosis strains. Antimicrob Agents Chemother. 1998;42:3035-3037.

59. Arora S. Eradication of Mycobacterium tuberculosis infection in 2 months with LL-3858: a preclinical study. Int J Tuberc Lung Dis. 2004;8(11 Suppl 1):S29.

60. Clinical Trials Registry, India. CTRI/2009/091/000741. Available at: http://www.ctri.nic.in/Clinicaltrials/pmaindet2.php?trialid=922 Accessed June 26, 2011.

61. Protopopova M, Hanrahan C, Nikonenko B, et al. Identification of a new antitubercular drug candidate, SQ109, from a combinatorial library of 1, 2-ethylenediamines. J Antimicrob Chemother. 2005;56:968-974.

62. Chen P, Gearhart J, Protopopova M, et al. Synergistic interactions of SQ109, a new ethylene diamine, with front-line anti-tubercular drugs in vitro. J Antimicrob Chemother. 2006;58:332-337.

63. Sequella Inc. SQ109 [Internet]. Rockville, MD: Sequella Inc; nd. Available at: http://www.sequella.com/docs/ Sequella_1 sheet_ SQ109_TB_v3.pdf. Accessed: Nov 4, 2011. Available at: http://www. sequella.com/docs/Sequella_1 sheet_SQ109_TB_v3.pdf. Accessed on June 25, 2011

64. Onajole OK, Belewa XV, Coovadia Y, et al. SQ109 analogues as potential antimicrobial candidates. Med Chem Res. 2011;20:1394-1401.

65. Jia L, Noker PE, Coward L, et al. Interspecies pharmacokinetics and in vitro metabolism of SQ109. Br J Pharmacol. 2006;147:476-485.

66. Sequella Incorporated. SQ609 therapeutic: preclinical indication. Treatment of pulmonary TB. Available at: http://www.sequella.com/ docs/Sequella_1sheet_SQ609_v1.pdf. Accessed June 26, 2011.

67. Sequella Incorporated. SQ641 therapeutic: preclinical indication. Broad spectrum antibiotic. Available at: http://www.sequella.com/docs/ Sequella_1 sheet_SQ641_v3.pdf. Accessed on June 26, 2011.

68. Chu DT, Fernandes PB. Structure-activity relationships in quinolone antibacterials. Antimicrob Agents Chemother. 1989;33:131-135.

69. Chu DT, Fernandes PB, Claiborne AK, et al. Structure-activity relationships in quinolone antibacterials: design, synthesis and biological activities of novel isothiazoloquinolones. Drugs Exp Clin Res. 1988;14:379-383.

70. Wang Q, Lucien E, Hashimoto A, et al. Isothiazoloquinolones with enhanced antistaphylococcal activities against multidrug-resistant strains: effects of structural modifications at the 6-, 7-, and 8-positions. J Med Chem. 2007;50:199-210.
71. Wiles JA, Song Y, Wang Q, et al. Biological evaluation of isothiazoloquinolones containing aromatic heterocycles at the 7-position: in vitro activity of a series of potent antibacterial agents that are effective against methicillin-resistant Staphylococcus aureus. Bioorg Med Chem Lett. 2006;16:1277-1281.

72. Pucci MJ, Cheng J, Podos SD, et al. In vitro and in vivo antibacterial activities of heteroaryl isothiazolones against resistant gram-positive pathogens. Antimicrob Agents Chemother. 2007;51:1259-1267.

73. Brighty KE, Gootz TD. Chemistry and mechanism of action of the quinolone antibacterials. In: Andriole VT, editor. The Quinolones. 3rd ed. San Diego, CA. Academic Press; 2000.

74. Cheng J, Thanassi JA, Thoma CL, et al. Dual targeting of DNA gyrase and topoisomerase IV: target interactions of heteroaryl isothiazolones in Staphylococcus aureus. Antimicrob Agents Chemother. 2007;51:2445-2453.

75. Pucci MJ, Ackerman M, Thanassi JA, et al. In vitro antituberculosis activities of ACH-702, a novel isothiazoloquinolone, against quinolonesusceptible and quinolone-resistant isolates. Antimicrob Agents Chemother. 2010;54:3478-3480.

76. Pucci MJ, Podos SD, Thanassi JA, et al. In vitro and in vivo profiles of ACH-702, an isothiazoloquinolone, against bacterial pathogens. Antimicrob Agents Chemother. 2011;55:2860-2871.

77. Stop TB Partnership. CPZEN-45. Available at: http://www.newtbdrugs. org/project.php?id=92. Accessed June 26, 2011.

78. Christophe T, Jackson M, Jeon HK, et al. High content screening identifies decaprenyl-phosphoribose $2^{\prime}$ epimerase as a target for intracellular antimycobacterial inhibitors. PLoS Pathog. 2009;5:e1000645.

79. Makarov V, Manina G, Mikusova K, et al. Benzothiazinones kill Mycobacterium tuberculosis by blocking arabinan synthesis. Science. 2009;324:801-814.

80. Pasca MR, Degiacomi G, Ribeiro AL, et al. Clinical isolates of Mycobacterium tuberculosis in four European hospitals are uniformly susceptible to benzothiazinones. Antimicrob Agents Chemother. 2010; 54:1616-1618.

81. Quro Science. Quro's milestone for Quro Science. Available at: http:// www.quroscience.com/qurofile/pipe/pipe.html Accessed June 26, 2011.

82. Stop TB Partnership. Q201 novel anti-TB agent. Available at: http:// dev.newtbdrugs.org/project.php?id=176. Accessed June 26, 2011.

83. Reddy VM, O’Sullivan JF, Gangadharam PR. Antimycobacterial activities of riminophenazines. J Antimicrob Chemother. 1999;3: 615-623.

84. TB Alliance. China pioneers R\&D Center. Available at: http://www. tballiance.org/new/portfolio/html-portfolio-item.php?id=14. Accessed June 26, 2011.

85. Stop TB Strategy. Building on and enhancing DOTS to meet the TB-related millennium development goals. Available at: http://www. ghdonline.org/drtb/resource/the-stop-tb-strategy-building-on-andenhancing-dot/. Accessed September 14, 2011.

86. Rowland R, McShane H. Tuberculosis vaccines in clinical trials. Expert Rev Vaccines. 2011;10(5):645-658.

87. Kaufman SHE, Hussey G, Lambert P. New vaccines for tuberculosis. Lancet. 2010;375:2110-2119.

88. Russell DG, Barry CE, Flynn JL. Tuberculosis: What we don't know can, and does, hurt us. Science. 2010;328:852-856.

89. Von Eschen K, Morrison R, Braun M, et al. The candidate tuberculosis vaccine Mtb72F/AS02A: Tolerability and immunogenicity in humans. Hum Vaccin. 2009;5:475-482.

90. Wingfield C. The Tuberculosis Vaccine Pipeline. In TAG Pipeline Report - 2010; Sec-2:140-148.

91. Beresford B, Sadoff JC. Update on research and development pipeline: Tuberculosis vaccines. Clin Inf Dis. 2010;50 Suppl 3:S178-S183.

92. Stop TB Partnership. Tuberculosis vaccine candidates. 2009. Available at: http://www.stoptb.org/wg/new_vaccines/assets/ documents/TB $\% 20$ Vaccine $\% 20$ Pipeline $\% 2009 \% 20$ final.pdf. Accessed September 14, 2011. 
93. Harrington M. Creating political will and scientific momentum to develop a point-of-care test for TB. Presented at the Fourteenth TB/ HIV Core Group Meeting of the Stop TB Partnership. Addis Ababa, Ethiopia, November 12, 2008.

94. Syed J. The Tuberculosis Diagnostic Pipeline. In TAG Pipeline Report 2010; Sec-2:107-124.

95. Check-Hayden E. Market overlap points to irresponsible use of tuberculosis drugs. Nat Med. 2011;17:635.

96. Palomino JC, Ramos DF, Da Silva PA. New anti-tuberculosis drugs: strategies, sources and new molecules. Curr Med Chem. 2009;16: 1898-1904.

97. Kinnings SL, Liu N, Buchmeier N, et al. Drug discovery using chemical systems biology: repositioning the safe medicine Comtan to treat multi-drug and extensively drug resistant tuberculosis. PLoS Comput Biol. 2009;5:e1000423.

98. Dutta NK, Mehra S, Kaushal D. A Mycobacterium tuberculosis sigma factor network responds to cell-envelope damage by the promising anti-mycobacterial thioridazine. PLoS One. 2010;5:e10069.

99. Dutta NK, Mazumdar K, Dastidar SG, et al. New patentable use of an old neuroleptic compound thioridazine to combat tuberculosis: a gene regulation perspective. Recent Pat Antiinfect Drug Discov. 2011;6:128-138.

100. Amaral L, Boeree MJ, Gillespie SH, et al. Thioridazine cures extensively drug-resistant tuberculosis (XDR-TB) and the need for global trials is now! Int J Antimicrob Agents. 2010;35:524-526.

101. Zheng F, Xie. J. The interaction topology of Mycobacterium tuberculosis genes responsive to capreomycin and novel clues for more drug targets. J Cell Biochem. June 15, 2011; 112:2716-2720.

102. Eoh H, Brennan PJ, Crick DC. The Mycobacterium tuberculosis MEP (2C-methyl-d-erythritol 4-phosphate) pathway as a new drug target. Tuberculosis (Edinb). 2009;89:1-11.

103. Rajni, Meena LS. Guanosine triphosphatases as novel therapeutic targets in tuberculosis. Int J Infect Dis. 2010;14:e682-e687.

104. Torres-Romero D, Jiménez IA, Rojas R, et al. Dihydro- $\beta$-agarofuran sesquiterpenes isolated from Celastrus vulcanicola as potential antiMycobacterium tuberculosis multidrug-resistant agents. Bioorg Med Chem. 2011;19:2182-2189.

105. León-Díaz R, Meckes M, Said-Fernández S, et al. Antimycobacterial neolignans isolated from Aristolochia taliscana. Mem Inst Oswaldo Cruz. 2010;105:45-51.
106. Zanetti S, Cannas S, Molicotti P, et al. Evaluation of the antimicrobial properties of the essential oil of Myrtus communis L. against clinical strains of Mycobacterium spp. Interdiscip Perspect Infect Dis. July 29, 2010. [Epub ahead of print.]

107. Gupta R, Thakur B, Singh P, et al. Anti-tuberculosis activity of selected medicinal plants against multi-drug resistant Mycobacterium tuberculosis isolates. Indian J Med Res. 2010;131:809-813.

108. Adhvaryu MR, Vakharia BC. Integrating herbal formulation with conventional ATT improves prognosis in complicated TB in addition to preventing hepatotoxicity. Abstract presented at the Shanghai International Tuberculosis Conference, Shanghai, China. March 18-20, 2011

109. Park SK, Kim JH, Kang H, et al. Pulmonary resection combined with isoniazid- and rifampin-based drug therapy for patients with multidrugresistant and extensively drug-resistant tuberculosis. Int J Infect Dis. 2009; $13: 170-175$.

110. Dravniece G, Cain KP, Holtz TH, et al. Adjunctive resectional lung surgery for extensively drug-resistant tuberculosis. Eur Respir J. 2009;34:180-183.

111. Yaldiz S, Gursoy S, Ucvet A, et al. Surgery offers high cure rates in multidrug-resistant tuberculosis. Ann Thorac Cardiovasc Surg. 2011;17:143-147.

112. Pandey R, Khuller GK. Antitubercular inhaled therapy: opportunities, progress and challenges. J Antimicrob Chemother. 2005;55: 430-435.

113. Garcia-Contreras L, Sung JC, Muttil P, et al. Dry powder PA-824 aerosols for treatment of tuberculosis in guinea pigs. Antimicrob Agents Chemother. 2010;54:1436-1442.

114. Zumla A, Wallis R, Doherty M, et al. Joint TDR/EC expert consultation on biomarkers in tuberculosis: report of the joint TDR/EC expert consultation to evaluate the potential roles of biomarkers in the management of HIV-infected and HIV-uninfected patients with tuberculosis, Geneva, Switzerland, July 2-3, 2008. Available at: http: apps.who.int/tdr/publications/tdr-research-publications/biomarkers/ pdf/biomarkers.pdf. Accessed Sep 15, 2011.

115. Spigelman M, Woosley R, Gheuens J. New initiative speeds tuberculosis drug development: novel drug regimens become possible in years, not decades. Int J Tuberc Lung Dis. 2010;14:663-664.
Clinical Pharmacology: Advances and Applications

\section{Publish your work in this journal}

Clinical Pharmacology: Advances and Applications is an international, peer-reviewed, open access journal publishing original research, reports, reviews and commentaries on all areas of drug experience in humans. The manuscript management system is completely online and includes a very quick and fair peer-review system, which is all easy to use.

\section{Dovepress}

Visit http://www.dovepress.com/testimonials.php to read real quotes from published authors. 